\title{
Relationship of Time and Learning Retention
}

\author{
Felix U. Kamuche, (Email: fkamuche@morehouse.edu), Morehouse College
}

Robert E. Ledman, Morehouse College

\begin{abstract}
This study explores the degree to which students' understanding, or knowledge, may deteriorate over time. Our specific focus was examining the importance of course sequencing in a curriculum. We measured student performance in quantitative business courses and found that, over time, the correlation between students' performance in those courses declined significantly. We further found that that decline was not linear.
\end{abstract}

\section{INTRODUCTION}

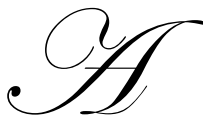

ny college professor who teaches junior or senior level courses has probably wondered if his or her students learned anything in prerequisite courses because they seem to not know some fundamental concepts. The concept of prerequisites is based on the premise that the learning of a subject is cumulative over several courses and one has to learn certain concepts before learning others. For instance, we do not expect a student to be able to successfully complete an advanced accounting course if he or she has never been exposed to basic accounting principles. This study focuses on assessing the extent to which the time between sequential courses may contribute to the loss of learning. Bahrick (1979) suggests that students do not retain the information acquired in a class for long after an exam. Higbee (1977) echoes that sentiment. More recent studies, however, show that although some information is forgotten (Conway, Cohen, \& Stanhope, 1991; Semb, Ellis, \& Aranjo, 1993), the retention loss is not as great as expected (Cooper and Greiner, 1971; Semb, Ellis, \& Montague, 1990). Wetzel, Konoske, \& Montague, (1983), Bahrick, (1984), and Bahrick and Hall (1991) found that retention can last up to fifty years.

The studies of retention have explored, at least somewhat, whether retention differs for different types of knowledge. Semb, Ellis, and Aranjo (1993) define four types of knowledge - recall, recognition, comprehension, and cognition. In their study, retention of recall knowledge was significantly lower than the other three. Semb and Ellis (1994) argue that there are two dimensions of the retention interval that can affect retention-length, and what occurred during the interval. With regards to the length of the interval, there are consistent findings that the amount retained declines in a non-linear manner (Bahrick, 1984; Bahrick and Hall, 1991; Glasnapp, Poggio \& Ory, 1978).

Farr (1987) suggests that the degree of original learning is the most important variable to long-term retention. Bahrick and Hall (1991), in a study of Spanish and mathematics students, found a strong correlation between the level of original learning and long-term retention. Specifically they studied the relationship between the number and level of courses completed and retention. The students who completed more and higher level courses retained more. The study reported here attempts to confirm this relationship by examining the correlation between a student's grade in one course and the student's grade in the subsequent related course.

\section{HYPOTHESES}

We hypothesized that the grades of students who take the two courses with a shorter time between them will correlate more highly and that correlation will decline over time in a non-linear manner as suggested by previous studies.

H1: The correlation between student grades in statistics and decision science will be significantly lower if the gap between the two courses includes the summer ( 3 months) when compared to the correlation between the grades if students take the courses with four weeks between the courses (fall to spring semesters). 
H2: The correlation between student grades in statistics and decision science will be significantly lower if students take the courses with a full semester and summer gap between them (fall and fall or spring and spring semesters) when compared to the correlation between the grades if the gap between the two courses includes only the summer (3 months).

H3: The decline in student retention, as demonstrated in hypotheses 1 and 2, is nonlinear.

\section{METHODOLOGY}

Over three years we tracked the class performance of male students in two quantitative business courses (statistics and decision sciences). The decision science course required use of concepts learned in statistics. Only students who took both courses from the same instructor were included in the data. The tests in these two courses were quantitative problem-solving based examinations. The professor uses the same test problems each term.

To measure the effects of time we compared students who took the two courses in three different sequences - fall to spring (a 4 week gap), spring to fall (a three month gap) and from spring to spring or fall to fall (an eight month gap).

\section{RESULTS}

The results of the correlation provide very strong support for hypothesis one. The students who took the courses in the fall to spring sequence had a correlation of 0.86 between their test scores in the two courses. Students who took the courses in a spring to fall sequence had a correlation of 0.71 between their test scores. That correlation is significantly lower that the correlation for the first group of students $(\mathrm{p}<.001)$. The support for hypothesis two is less strong but indicates a further decline in retention. Students who took the two courses in a spring and spring or fall and fall sequence had a correlation of 0.68 between test scores in the two courses. This is significantly lower than the previous test group of students who took the two courses in a spring to fall sequence $(p<06)$.

These results clearly suggest a non-linear decline in student retention of knowledge, thus supporting hypothesis three. Examining the total decline in test performance over time further supports that conclusion. For instance, $91 \%$ of the drop in correlations over eight months (fall to fall or spring to spring) is accounted for in the first three months as suggested by the decline in correlation for those students who took the course sequence in spring and fall. More than $50 \%$ of the correlation decline occurred after one month as shown by comparing correlation results for students who took the two courses with only a semester break between compared to those who took the two courses in the spring and fall with a summer break.

To confirm that the correlations represented a decline in performance we performed an analysis of variance shown in Table 1. The results of that analysis were significant at the $\mathrm{p}<.002$ level. Those results make it clear that the class performance scores were in fact declining over time.

Table 1: Analysis of Variance

\begin{tabular}{|l|c|c|c|c|c|}
\hline ANOVA & df & SS & MS & F & Significance F \\
\hline Regression & 1 & 388.2994912 & 388.2995 & 9.538943 & 0.002426 \\
\hline Residual & 140 & 5698.946988 & 40.70676 & & \\
\hline Total & 141 & 6087.246479 & & & \\
\hline ANOVA & df & SS & MS & F & Significance F \\
\hline Regression & 1 & 388.2994912 & 388.2995 & 9.538943 & 0.002426 \\
\hline Residual & 140 & 5698.946988 & 40.70676 & & \\
\hline Total & 141 & 6087.246479 & & & \\
\hline
\end{tabular}




\section{DISCUSSION}

This study contributes to the existing literature because of its specific design. Previous studies have relied on tests to assess the retention of learning. The typical approach was to give students a test on a subject some time after completing the course. This study is the first we could find that examines actual student class performance in courses that require the use of knowledge learned in a previous course, specifically a pre-requisite course. Since the sample was drawn from those students who took both courses from the same professor, the issue of what material was covered with what degree of emphasis does not come into play.

This study suggests that the sequencing of courses can be important to students' success. One surprising aspect of the findings is the extent of decline in retention in the first weeks after the first course was completed. Over $50 \%$ of the retention decline seen after three months is evident after only four weeks. This finding seems to be consistent with the views of Bahrick (1979) and Higbee (1977). However, as Semb, Ellis and Aranjo (1993) found, retention of recall knowledge seems to decline more rapidly than other types of knowledge. Since the courses involved in this study required a significant use of recall of concepts and methods from the statistics course to the decision science course, the substantial early drop in knowledge retention may be a manifestation of what Semb, Ellis, and Aranjo observed.

Farr (1987) and Bahrick and Hall (1991) found that the degree of learning was correlated to the retention. Those findings suggest that students who did well in the first course (statistics) should also retain more knowledge, and therefore do well in the subsequent decision science course. The high correlation (.86) between student grades for those who took the two courses with only a four-week semester break is consistent with the conclusions of Farr (1987) and Bahrick and Hall (1991).

This study has implications for course scheduling, advising, and curriculum planning. For example, students should be encouraged to plan their academic sequences in a manner that takes these results into account. It is fairly standard practice at our institution, for instance, to strongly encourage students to take all math requirements in a semester-to-semester pattern and not "take a break" for a semester. The role of pre-requisites and the way courses are scheduled to facilitate minimizing time between closely dependent courses may need to be given more consideration in schedule planning by department chairs and deans. For example, it may make sense to offer more sections of a course like statistics in the fall and subsequently offer more sections of decision science in the spring to accommodate the maximum number of students. A similar pattern might make sense in other course like languages, accounting, and mathematics. This kind of course scheduling pattern would facilitate more students taking sequential courses with minimal time between them.

\section{LIMITATIONS}

Clearly further studies are needed to confirm these findings, especially in other disciplines. It should be noted, though, that the findings in this study agree with previous studies cited and those studies included a variety of subject matter ranging from social sciences to languages, to laboratory sciences. One limitation in this study relates to student motivation. Our sample is derived from a student population that has well above average SAT scores who are attending a highly regarded liberal arts college. The sample size of 141 in this study was large enough to likely account for variations in GPA. Another area in need of more study is possible gender differences. The sample in this study is all male since our institution is all male. While none of the previous studies cited noted any differences based on gender, that is an area that needs further study specifically exploring the issue of possible gender differences.

\section{REFERENCES}

1. Bahrick, H. P. (1979). Maintenance of knowledge: Questions about memory we forgot to ask. Journal of Experiment Psychology: General, 108:296-308.

2. Bahrick, H. P. (1984). Semantic memory content in permastore: Fifty years of memory for Spanish learning in school. Journal of Experiment Psychology: General, 113:1-29. 
3. Bahrick, H. P. and Hall, L. K. (1991). Lifetime maintenance of high school mathematics content. Journal of Experiment Psychology: General, 120:20-33.

4. Conway, M. A., Cohen, G. and Stanhope, N. (1992). Very long-term memory of knowledge acquired at school and university. Applied Cognitive Psychology, 6:467-482.

5. Cooper, I. L. and Greiner, J. M. (1971). Contingency management in an introductory psychology course produces better retention. Psychological Record, 21:391-400

6. Farr, M. J. (1987). The Long-term Retention of Knowledge and Skills: A Cognitive and Instructional Approach. New York: Springer-Verlag.

7. Glasnapp, D. R., Poggio, J. P., and Ory, J. C. (1978). End-of-course and long-term retention outcomes for mastery and nonmastery learning paradigms. Psychology in the Schools, 15:595-603.

8. Higbee, K. L. (1977). Your Memory: How it Works and How to Improve It. Englewood Cliffs, NJ: Prentice Hall.

9. Semb, G. B. and Ellis, J. A. (1994). Knowledge taught in school: What is remembered? Review of Educational Research, 64:253-286.

10. Semb, G. B., Ellis, J. A. and Aranjo, J. (1993). Long-term retention of knowledge learned in school. Journal of Educational Psychology, 85:305-316.

11. Semb, G. B., Ellis, J. A. and Montague, W. E. (1990). Long-term memory for knowledge taught in school. (Tech. Rep. No. NPRDC TR-91-1). San Diego: Navy Personnel Research and Development Center.

12. Wetzel, S. K., Konoske, P. I., and Montague, W. E. (1983) Estimating skill degradation for aviation antisubmarine warfare operators (AWs): Loss of skill and knowledge following training. (Tech. Rep. No. NPRDC TR-83-31). San Diego: Navy Personnel Research and Development Center. 